\title{
LAS CIENCIAS SOCIALES: UNA CONTRIBUCION FUNDAMENTAL
}

\author{
Antonio Gorri Goñi
}

\section{Introducción}

Es evidente que el hombre actual se halla inmerso en un proceso de profundo cambio social, inducido fundamentalmente por la industrialización y la influencia de las tecnologías avanzadas y en el que las dimensiones científica y económica constituyen una realidad primordial.

Las conquistas alcanzadas por el desarrollo tecnológico-económico son realmente espectaculares y posiblemente la primera función de las Ciencias Sociales sea la de su reconocimiento y su estimulación para su progreso permanente hacia el futuro.

Sin embargo, junto a la admiración por sus innumerables logros obtenidos, quizás sea igualmente necesario constatar que el desarrollo científico-industrial no abarca la totalidad de la realidad humana y que lo propiamente humano, social y psicológico configuran, asimismo, una dimensión intrínsecamente esencial.

Dicho proceso de cambio social ha creado paralelamente un marco distinto de relaciones (laborales, económicas, políticas, ideológicas...) que establece unas nuevas formas de convivencia social. En ellas el progreso ha sido también incuestionable. La existencia conjunta, sin embargo, de una amplia y profunda sintomatología patológica social es indicio de que no todo marcha con satisfacción en nuestra sociedad y de que posiblemente dimensiones vitales del ser humano han sido olvidadas total o parcialmente.

Nuestra hipótesis es que, junto al desarrollo científico-tecnológico es preciso desarrollar simultáneamente lo humano-social y psicológico y que, incluso dentro del ámbito meramente positivo, es necesario recuperar la dimensionalidad humana de la esfera económico-industrial. El papel que las Ciencias Sociales pueden desempeñar en esta doble vertiente de equilibrio armónico es, en nuestra opinión, esencial. 
Para ilustrar la aportación de las Ciencias Sociales al hombre actual, pretendemos efectuar un breve recorrido histórico-científico y enumerar, a modo de ejemplo, algunas de sus contribuciones contemporáneas. Incluso en un entorno tecnológico altamente automatizado, la toma de decisiones corresponde - $\mathrm{O}$ debe corresponder - al propio hombre al que las Ciencias Sociales tratan de analizar.

\section{La Filosofía Social: una tensión permanente hacia la comprensión del hombre y de la sociedad}

Una de las primeras aportaciones que encontramos en la historia de las Ciencias Sociales es, sin duda, su esfuerzo por analizar en profundidad la realidad humana y su proyección social. La Filosofía Social representa, a tal respecto, un hito fundamental.

Ciertamente, la historia del Pensamiento es la historia de sus intentos por responder de un modo eficaz a la problemática planteada por el hombre a lo largo de su proceso social. El Pensamiento no es otra cosa que el conjunto de las experiencias vitales comunes a todos los hombres. La Filosofía es la perspectiva del hombre, de la tensión dialéctica del pensamiento para, trascendiéndose a sí misma desde su propia intencionalidad, orientarse en las contradicciones de nuestro tiempo y encontrar, como consecuencia, el modo de superarlas.

La Fenomenología, el Existencialismo, el Estructuralismo, el Personalismo, el Marxismo... constituyen, entre otros y cada uno desde su respectiva óptica, momentos culturales esenciales que tratan de contribuir a la explicación y transformación de la existencia humana.

La Filosofía contemporánea, en efecto, nació como respuesta a dos tipos de cuestiones: a) los temas planteados por las crisis y cambios profundos de la sociedad y b) los interrogantes suscitados al hombre por el desarrollo de las ciencias y de las técnicas. Ambos ponían en tela de juicio las ideas y los valores tradicionales e interpelaban a los pensadores a reflexionar sobre el fondo de los problemas.

Desde una perspectiva histórica - en vísperas de la segunda guerra mundial - la respuesta a los planteamientos fundamentales no provenía ya de las doctrinas filosóficas clásicas que habían predominado en las universidades europeas. Hamelin, Brunschvicg, Bergson... no parecían poder ofrecer los instrumentos intelectuales adecuados necesarios para pensar sobre las nuevas realidades relativas a la historia, la acción y la subjetividad personal.

El punto de partida de Husserl, representó una crítica al objetivismo, a la concepción positivista y pragmática de la ciencia, que ponía en cues- 
tión a la vez el materialismo mecanicista y el idealismo trascendental de tipo kantiano o brunschvicgiano.

Insertado en la óptica fenomenológica, Husserl pretendió el retorno a lo fundamental a través de la intencionalidad y de la responsabilidad hasta tal punto que Francis Jeanson (1952) lo describía acertadamente afirmando que «la phénoménologie est un reveil de responsabilité» (p. 93).

Sin embargo, la fenomenología de Husserl acabaría haciendo abstracción de todo elemento social e histórico. Enmanuel Levinas (1949) lo reconoce abiertamente al indicar que «la conscience dont la phénoménologie fournit l'analyse n'est en aucune facon engagé dans la realité ni compromise par l'histoire» (p. 35). Esta carencia privaba a la aportación del pensamiento hursseliano de una dimensión fundamental a pesar de su indudable valor intencional.

El Existencialismo, por su parte, nace como respuesta a una situación sociohistórica concreta que alcanza su punto culminante en la crisis económica general de 1929, en las tensiones internacionales que preludiaban la segunda guerra mundial, en la afirmación del socialismo y en el desarrollo de los fascismos.

El Existencialismo tiene sus precursores no sólo en Kierkegaard y Stirner, en Dostoievski y Nietzsche, los cuales vivieron y expresaron los temas existencialistas tras las primeras grandes crisis actuales, sino también en el existencialismo ruso de Berdiaev y de Chestov y en el existencialismo alemán de Heidegger y Jaspers, que reflejaban ideas similares entre las dos guerras mundiales.

Todos ellos expresaban, en una mutua transposición de experiencias, una idéntica realidad sociopolítica: el resquebrajamiento de viejos regímenes que preludiaban el derrumbamiento de los cuadros sociales, políticos, ideológicos y religiosos que hasta ese momento habían significado la seguridad y estabilidad en la vida individual y social.

La filosofía anterior había sido cuestionada y las nuevas ideologías eran requeridas ahora por las actuales circunstancias en la búsqueda de una respuesta existencial.

En pura consecuencia, como ya hemos expresado en otro momento (A. Gorri, 1986), tres eran los principales grupos de temas que, de Jaspers a Heidegger en Alemania y de Marcel a Sartre en Francia, centraron la atención del pensamiento existencialista:

En primer lugar, los temas encaminados a describir y reflejar fielmente la realidad de una situación social que, como hemos indicado, estaba impregnada de dramatismo económico, político e ideológico. A ello responde, como no podía ser de otro modo, el carácter pesimista y angustioso con que popularmente se identifica el concepto existencialista. 
En segundo lugar (aspecto frencuentemente olvidado), los temas que expresan el intento de reacción, de búsqueda de una posibilidad de recuperación, ante la situacion anterior. Frente al ser desgarrado de Jaspers que se encontraba ahí, sin sentido, en la facticidad de Heidegger, era preciso elaborar un proyecto cuya esencia dependía exclusivamente de la decisión humana. Existir, según la originalidad ofrecida por la filosofía de la existencia, debe ser entendido en el sentido transitivo del verbo. La existencia es una trascendencia. Su existir es intencionalidad. El Hombre, lejos de constituir una esencia definida de antemano y desde el exterior, debe en cada instante crear su futuro y sus razones de vivir. Su porvenir depende de él. En ese salto permanente del hombre hacia adelante de sí mismo, define su libertad la cual es, por ello mismo, acción y trascendencia. Como decía Lequier: la existencia es hacer y al hacer hacerse y no ser otra cosa que lo que se hace. El hombre, dirá Sartre, en Situations I, es el ser cuya aparición hace que el mundo exista.

En tercer lugar, el existencialismo asume los temas que recogen simultáneamente ambos aspectos anteriores — negativos y positivos- de conflictividad y de reacción, de desesperanza y acción, que aparecen como dos polos indisociables dentro del marco unitario de la fenomenología. Ambos procesos son complementarios y característicos del existencialismo y de la vida misma. El uno, para proyectar el mundo, para tomar distancias con relación a él; el otro, para experimentar, en el hecho mismo de este desarraigamiento, nuestro poder absoluto de elección y de responsabilidad. Paradoja extrema en la que la libertad, momento supremo del hombre, no es plenitud sino, por el contrario, una falta, una ausencia, un agujero en el ser. La nada llega a ser el tema central en el drama de la existencia y la realidad humana es una falta de ser.

Sintetizando esta perspectiva existencialista, es necesario constatar que su aportación más importante probablemente sea su empeño constante por eliminar la cosificación de la realidad humana, su intento de explicar lo que hay de indeterminación, de decisión autónoma, en el acto libre y de realizar esa interpretación dentro de un marco dialéctico. Sin embargo (sobre todo en lo que respecta a la óptica sartreana), es preciso criticar su concepción en tanto que radicalizando la respectiva negatividad y positividad del pour-soi y en-soi y pretendiendo la total pureza de aquél, problematiza hasta el extremo el reconocimiento pleno de cada realidad: subjetividad-objetividad, individualidad y presencia del otro, libertad original y situación, autonomía e historia.

El Estructuralismo, a su vez, había de desarrollar una idea maestra: afirmar la primacía de la relación respecto al ser y del todo con relación a las partes. El Estructuralismo, en su dimensión doctrinal abstracta, pretendía reducir toda la realidad a la estructura, sin pasar nunca de la es- 
tructura a la actividad humana que la engendra y sin reconocer, como lo exige un estructuralismo dialéctico, que el método estructural no puede revelar toda su fecundidad más que por su complementariedad con el método genético del que $\mathrm{H}$. Wallon ha dado un ejemplo en su aplicación a las ciencias humanas.

Ciertamente, De Saussure, Jacobson o Lévi-Strauss no pretendieron que la estructura abarcaba la totalidad del conocimiento pero, por ejemplo, Michel Foucault (1966) en su Les mots et les choses tras presentar la biología, la economía y la lingüística como dimensiones esenciales, afirma que ellas constituyen «sans résidu, le domaine entier de la connaissance de l'homme» (p. 369).

Es posiblemente esta disolución del hombre en las ciencias, su absorción o eliminación por las mismas, lo que constituye su crítica más importante. Y, ello, a pesar de contar entre sus muchos méritos los hechos de haber intentado un acercamiento a la naturaleza, de tratar de reencontrar los lazos que nos ligan a la humanidad milenaria o de acentuar —en la línea de Lacan, Luria, Kaplan, Werner etc.- la determinación que el animal humano recibe de los distintos sistemas simbólicos del orden socio-cultural.

El Personalismo, nacido en un contexto social similar al del existencialismo: de fuertes convulsiones sociales, de avances científicos, y de crisis de las ideologías y valores, trata de responder al planteamiento del hombre de su época, esta vez desde una óptica religiosa, católica, conciliada con el compromiso con la historia y con la vida social. Pretende mostrar en la inmanencia de la historia profana la emergencia de la trascendencia.

El Personalismo, propiamente más un movimiento que un sistema filosófico, debe su orientación general a Jean Lacroix y su impulso y animación a Enmanuel Mounier. Su preocupación central no es solamente establecer la responsabilidad del sujeto, sino también expresar su situación dentro de la naturaleza y de la historia. Se trata, según la expresión de Lacroix en Marxisme, existencialisme, personalisme, de «replonger (au sujet) dans le monde physique et social» (p. 3).

La tarea esencial era reconciliar a Marx y Kierkegaard. Sus rasgos esenciales se definen por oposición al marxismo y al existencialismo. Al primero le reprocha la subestimación del sujeto y al segundo la no suficiente referencia a la trascendencia. El Personalismo, escribe Mounier (1946), tratando de escapar a la vez al marxismo y al moralismo «est un effort total pour comprendre et dépasser l'ensemble de la crisis de l'homme du XX ${ }^{\mathrm{e}}$ siècle» (p. 48).

Sin embargo, este personalismo que, en su intento de oponerse simultáneamente al materialismo marxista y al idealismo desencarnado, 
pretendía mantener a la vez la primacía del espíritu y su encarnación, fue avocado a un cierto confusionismo y eclecticismo. En su esfuerzo por aprehender el orden total de lo real, no pudo conjugar una transformación profunda que sería exclusivamente económica y un cambio que fuera puramente espiritual. Su paso de Kierkegaard a Marx, más que una superación constituye una yuxtaposición. Más que una síntesis una mezcla no transparente. Su lucha por mantener la tensión entre lo político y lo profético, traducido en su eclecticismo filosófico, adolece de un insuficiente análisis histórico concreto. - A pesar de ello, representó un movimiento relevante, sincero y entusiasta, en la defensa del hombre.

Finalmente, la contribución del Marxismo se centra, desde su óptica específica, en el análisis de las relaciones entre el capital y el trabajo.

A partir de un matizado y profundo estudio, Marx elabora su teoría económico-política. Los Anales Alemanes de 1843 pusieron ya de manifiesto la incompatibilidad de Marx y Ruge, por la inclinación del primero hacia las tesis comunistas frente a los principios democrático-liberales y tradicionalistas del segundo. Los Manuscritos de 1844 abordarían los dos grandes temas de: la crítica de la economía política y el marxismo. El Manifiesto Comunista de 1848, apoyándose en sus anteriores escritos de La Sagrada Familia (1844), La ideología alemana (1845) y en la ruptura con el primitivo comunismo francés expresada en Miseria de Filosofía (1847), define la lucha de clases como el motor de la historia.

A través de La contribución a la crítica de la economía política (1859), Salario, precio y ganancia (1865) y fundamentalmente de los tres libros de su obra clave El Capital (1867, 1885 y 1894, respectivamente), dedicaría su esfuerzo a la crítica de la economía política clásica. La idea central del Capital se desarrolla en orden al desmantelamiento del sofisticado edificio de construción y cobertura ideológico-jurídica del poder que Marx veía en la burguesía. «Dans une societé capitaliste - afirmaba (1901) - tout producteur... est dominé par les idées de l'organisation sociale au sein de laquelle il vit» (p. 14).

En su opinión, no existe jamás un movimiento político que al mismo tiempo no sea social. Solamente en un orden de cosas en la cual no existan clases ni antagonismos —-sostenía en Miseria de Filosofía (1969)— «las evoluciones sociales dejarán de ser revoluciones políticas» (p. 240).

La aparición de Materialisme et empiriocriticisme en 1928, abriría nuevas perspectivas para jóvenes filósofos como Politzer, Lefebre, Morhange y para otros que, como Wallon, Langevin, Cohen, Prenant, Maublanc y Labérenne, analizarían el materialismo dialéctico en su aplicación a las ciencias.

El dogmatismo inmovilista de muchos de sus continuadores, empero, unido a la parcialidad de algunos de sus enfoques llevarían al marxismo, 
en opinión de diversos autores, a una falta de rigor y de ojetividad que posteriormente abocaría a la eliminación del concepto de subjetividad y de libertad. Conceptos que pensadores como Adam Schaff, Georges Luckas y Louis Althusser tratarían de recuperar en la búsqueda de lo que ellos denominaron «un socialismo auténtico». Nadie duda, en cualquier caso, que la aportación del marxismo al análisis de la naturaleza y de la historia ha sido fundamental.

En suma, esta breve perspectiva histórica de algunas de las ideologías de nuestro siglo nos ejemplariza que la Filosofía Social constituye una contribución esencial en su intento por comprender y explicar la realidad humana y por su esfuerzo por responder a los interrogantes que la transformación científica y social ha planteado en cada momento de su desarrollo.

Evidentemente, cada filosofía, cada pensamiento, ofrece su aportación desde su enfoque particular. Es posible que desde una sociedad constitucional, democrática, plural, no solamente ningún pensamiento pueda ni deba ser excluido, sino que el diálogo abierto, dinámico y respetuoso que dimane de la autocrítica leal de los propios sistemas deba incitar a la investigación rigurosa para extraer de su contraste dialéctico cualquier dimensión positiva que esclarezca el existir humano y contribuya a la realización de su proyección futura. Cada vez más, el diálogo debe caracterizar el estilo de la vida intelectual y política de cada país como contribución fundamental del Pensamiento al hombre y a la sociedad.

\section{La relevante contribución Antropológico-Social}

Otra de las Ciencias Sociales, de enorme trascendencia en la cultura contemporánea es, sin duda, la Antropología.

Como es sabido, etimológicamente Antropología significa «estudio del hombre». Ahora bien, sorprendentemente no encontramos en la Antropología un único concepto o una única respuesta para la pregunta «¿qué es el hombre?». Posiblemente, una de las razones de esta no unificación conceptual esté en el peculiar carácter de la misma.

Existe una característica radical que cualifica a la Antropología y la hace diferenciarse de las demás ciencias: la multivalencia y ambigüedad de su objeto, el hombre.

Las ciencias, en general, estudian al hombre como una serie más de procesos biológicos, fisiológicos, económicos y sociológicos a niveles perfectamente determinados. La Antropología no es un saber de este tipo, aunque no deja de ser un saber perfectamente positivo. Su objeto no 
se agota en uno solo de los niveles señalados, sino que es implicativo e integral. Su objeto formal no es el hombre en cuanto conjunto de fenómenos biológicos, económicos o sociales sino el hombre en cuanto humano, en cuanto un viviente de tal naturaleza específica que integra todos los niveles que afectan en una peculiar unidad dinámica de modalidad propiamente humana. Es un saber acerca del hombre en cuanto hombre. Es lo que el profesor Cencillo (1970) ha denominado «Antropología Integral» o la peculiar «positividad del saber antropológico» (pp. 11-46).

Naturalmente, supuesta la aportación de este enfoque integral, la Antropología posee diferentes orientaciones, ramas o niveles entre los que podemos destacar los siguientes: Biológico (Antropología biológica y genética), Etnográfico y Paleontológico (Etnografía descriptiva de razas y de etapas de evolución humana), Etnológico (Etnología o reflexión sistemática acerca del fenómeno socio-cultural de las razas), sociológico (Antropología social), Cultural propiamente dicho (Antropología cultural), Psicológico (Antropología psicológica), Psicoanalítico (Antropología psicoanalítica) y Filosófico (Antropología filosófica).

Cada una de las Antropologías o ramas de la Antropología que estudia los respectivos niveles citados, se halla perfectamente justificada y cuenta con unos métodos específicos, exigidos por la positividad de su correspondiente objeto formal. Dando por supuesto que se trata de un saber que participa simultáneamente del carácter de las ciencias nomotéticas y del de las idiográficas, constituye un proceso de conocimiento metódicamente llevado, a partir de unas técnicas de la observación (trabajos de campo, antropometría, encuestas, tests...), mediante unas técnicas de control (matemáticas y no matemáticas) y tendente a una totalización sistemática que haga tomar una conciencia cada vez más amplia y más profunda acerca de lo que el hombre y todas sus realidades son y significan.

La aportación de la Antropología, por tanto, globalmente considerada, se centra en el estudio de cada uno de los niveles mencionados, a través de sus técnicas y métodos respectivos, pero sin olvidar su integración en una perspectiva que intenta hacerse cargo de la realidad humana en su totalidad.

Históricamente, la contribución de la Antropología se patentiza en diversos momentos y autores representativos. Omitiendo, por razones de brevedad, las aportaciones, desde su nacimiento en el siglo XVIII, de P. Lafiteau, J. Kranft, Linneo, C. Meiners... y del siglo XIX a través de Le Play, F. Desmolins, K. Ritter, J. J. Bachofen etc., observamos que a finales de este siglo XIX los criterios metodológicos y las concepciones que se venían sucediendo eran principalmente: el evolucionismo, el ambientalismo y, a partir de Ratzel en Alemania y de Miss A. W. Buckland en Inglaterra, el difusionismo. 
Este difusionismo se generaliza años después con la teoría de F. Graebner según la cual los focos originarios de cultura se acumulan estratigráficamente a lo largo de los milenios en áreas culturales constituyendo los kulturschichten o estratos culturales. Consecuentemente, el método histórico de la Etnología habría de proceder desarticulando analíticamente tales «estratos» y reconstruyendo el pasado dinámico de cada uno de ellos. Hacia los años veinte de nuestro siglo, Graebner contaría con tres discípulos ilustres: W. Schmidt, W. Koppers y M. Gusinde cuya aportación iba a ser realmente cualificada.

También en el primer cuarto del s. XIX, Nelson adapta la teoría de «época-y área» donde supone existir en las culturas una superposición de complejos de rasgos a partir de los cuales pueden ser detectadas relaciones temporales.

Otro gran antropólogo americano, aunque nacido en Alemania, Franz Boas, profesor e investigador en la Columbia University de New York, ofreció la aportación de dividir América en áreas culturales ciertas, insistiendo en la observación de los hechos y los datos obtenidos en trabajos de campo y valorados a la luz de un conjunto de criterios complementarios: históricos, psicológicos, biológicos y económicos. Con F. Boas puede decirse que nace la Antropología actual ya en un estado aceptable de madurez. El mismo forma un grupo excelente de discípulos -A. L. Kroeber, R. Benedict, M. Mead, R. Linton, E. Sapir...- que constituyen los nombres más creadores y representativos de la Antropología americana.

La aportación de la Escuela inglesa de principios de siglo, con G. Elliot-Smith, W. J. Perry y W. H. R. Rivers, es, por su parte, más bien escasa. Su empeño por hacer proceder a todas las culturas de un foco único y común: Egipto, le restringe a apreciaciones subjetivas, les aleja progresivamente de la observación directa y desprestigia, consecuentemente, su investigación.

En Suiza, G. Montandon, ofrece un mapa universal de distribución cultural a base de cycles culturels asociados a una serie de elementos permanentes y comunes denominados compagnonage traditionel. Sin embargo, al igual que ocurre en Graebner, su trabajo adolece de cierto control positivo y carece de un criterio metodológico reductor.

En París, una corriente de etnólogos estimulados por las publicaciones de L'Année Sociologique de E. Durkeim, pretende ofrecer una serie de trabajos de campo, de material sociológico, de descubrimientos etnográficos destinados a nutrir la reflexión sociológica del futuro. Pero, su eliminación del dato individual y del factor biológico, como si todo ocurriese en el análisis de las culturas con una regularidad infalible, relativiza al ser humano y el fenómeno humano como totalidad queda falseado $\mathrm{o}$, al menos, mutilado. 
No obstante, de esta Escuela nacería una contribución importante. De ella surgirían nombres tan relevantes como H. Lubert, L. Lévi-Bruhl, G. Gurvitch y M. Mauss. Mauss, es, a su vez, maestro e iniciador de LéviStrauss e influye en Firth, Radcliffe-Brown, Evans-Pritchard, Malinowski y Otros.

Así surge la aportación de la Antropología moderna que supone, en el declinar de la Etnología y en el auge de la Sociología, una síntesis entre las Ciencias Históricas, Sociales y la Antropología propiamente dicha.

Lévi-Strauss, Malinowski y Radcliffe-Brown, habían de asegurar el predominio a la Antropología de orientación social. En el estudio de la estructura social, mantendrá Radcliffe-Brown (1986), «la realidad concreta que nos ocupa es la serie de relaciones realmente existentes en un momento dado que ligan entre sí a ciertos seres humanos» (p. 219), si bien Lévi-Strauss (1976), desviándose del dinamismo diacrónico de Radcliffe-Brown, matiza que «la estructura social no puede reducirse sin más al conjunto de relaciones observables en una sociedad determinada» (p. 251).

Posteriormente, G. Roheim, H. Marcuse, A. Mitscherlich y otros, establecen, desde ángulos diversos, un acercamiento entre los análisis psicoanalíticos y los estudios comparativos antropológicos.

Desde una perspectiva más actual, los antropólogos se esfuerzan por extraer sus aportaciones desde los distintos ámbitos de la Antropología Filosófica, Cultural, Psicológica, Social y Aplicada. Así:

E. Cassirer (1977), en su texto sobre Antropología Filosófica, trata de profundizar en el concepto de sociabilidad. La sociabilidad en cuanto tal - afirma este autor- no es una característica exclusiva del hombre. En los llamados estados animales (por eiemplo entre las abejas y las hormigas), encontramos igualmente una neta división de trabajo, así como una organización social sorprendentemente complicada. Pero, en el caso del hombre, puntualiza Cassirer, no encontramos sólo como en los animales una sociedad de acción sino también una sociedad de pensamiento y sentimiento. «El lenguaje, el mito, el arte, la religión y la ciencia, representan los elementos y las condiciones constitutivas de esta forma superior de sociedad» (p. 327).

Clifford Geertz (1990), por su parte, en su Interpretación de las culturas, recogiendo los trabajos que durante quince años ha elaborado en torno a lo que es la cultura, destaca el papel que ésta desempeña en la vida social y esboza como debería estudiársela adecuadamente. Junto a ello, analiza igualmente esferas relativas al desarrollo económico, la organización social, la historia comparada y la ecología cultural. Su preocupación es siempre contactar con la realidad ya que, como él mismo 
afirma, «me siento incómodo cuando me alejo demasiado de los hechos inmediatos de la vida social» (p. 13).

George De Vos (1981), profesor de Antropología, Psicología y Sociología en la Universidad de California, Berkeley, se refiere desde su Antropología Psicológica al ser humano en cuanto aprendiz de cultura y a las respuestas psicológicas al cambio en la sociedad y en la cultura. El estudio intercultural integrado de la socialización, afirma De Vos, «es un área de la Antropología relativamente desconocida hasta el momento y que presenta numerosas oportunidades para la investigación futura» (p. 94).

Lucy Mair (1982), en su Introducción a la Antropología Social, describe como conceptos claves de la misma: la estructura social, el grupo, el status, la función etc. En su opinión, la aportación de la disciplina se refiere, entre otras, a los conjuntos institucionales y culturales; los grupos de parentesco y edad; las normas que establecen la filiación (matrilineal o patrilineal) y las expectativas matrimoniales (exogamia y endogamia); la organización política de carácter tribal o pre-estatal; la producción y el intercambio de bienes en economías de tecnología simple; la magia y el totemismo; las creencias y rituales religiosos; los problemas específicos creados por el cambio social y las relaciones entre las razas.

De este modo, la Antropología aplicada pretende constituirse en la ciencia del control consciente de las sociedades humanas en los procesos de aculturación y cambio. Antropología aplicada que, en opinión de R. Bastide (1977), «será tanto más sólida cuanto más auténticamente científica sea la Antropología teórica sobre la que descanse» (p. 8).

No es de extrañar, por ello, que Marwin Harris (1989), al describir la Antropología como el estudio de la humanidad, de los pueblos antiguos y modernos y de sus estilos de vida, haya afirmado que «más que nunca, la perspectiva global y comparativa de la Antropología facilita una estructura indispensable para la comprensión del mundo moderno, iluminando aspectos diversos de la experiencia humana» (p. 9).

Con todo ello, concluye L. Mair (1982) los antropólogos desean ofrecer sus aportaciones para que «los representantes de la autoridad y en especial los profesionales que ocupan los niveles inferiores de la jerarquía, que son quienes tienen mayor contacto con los habitantes de las aldeas, conozcan mejor el análisis de la sociedad» (p. 287).

En síntesis, la Antropología tanto en su análisis integral del hombre, como en el análisis específico de los niveles que lo integran, representa un esfuerzo admirable por contribuir al conocimiento de la realidad humana y social. Las Escuelas y Autores que, desde una perspectiva histórica y próxima hemos mencionado, representan un claro exponente de ello. 


\section{La aportación científica de la Sociología}

Junto a la Filosofía y la Antropología, la Sociología constituye, obviamente, otra de las Ciencias Sociales cualificadas de nuestro tiempo.

La respuesta al cuándo, por qué, cómo y para qué surge la Sociología, nos ofrece de algún modo una idea global de su aportación a la época contemporánea.

En líneas muy generales y esquemáticas, describe J. F. Tezanos (1990), 1a Sociología aparece prácticamente en nuestro tiempo histórico (la era industrial) y precisamente al hilo del surgimiento y desarrollo de la sociedad industrial.

La Sociología aparece porque se han alcanzado las condiciones de madurez adecuadas en las circunstancias que pueden conducir a su desarrollo, a saber: una gran sensibilidad y atención a lo social (como consecuencia del impacto de los intensos procesos de cambio ocurridos) y unas condiciones intelectuales adecuadas (liberación de dogmas y trabas en el desenvolvimiento de la reflexión intelectual, tendencia a la búsqueda de visiones desencantadas de la realidad, más allá de las explicaciones mágicas y sacralizadas, etc).

La Sociología surge por un proceso secuencial de evolución de los saberes sociales en una dirección de avance hacia una mayor especialización, diferenciación y complejización, en la que el primer hito fundamental fue la autonominación de la Ciencia Política, de la Religión y de la Moral (con Maquiavelo básicamente), el segundo hito fue la aparición y desarrollo de la Ciencia económica (como requisito de la lógica de la sociedad industrial) y el tercero el surgimiento de la Sociología (como intento de dar una respuesta a los procesos de cambio, de conflicto y de desorganización social que también implicó la dinámica de la sociedad industrial.

La Sociología surgió, a corto plazo, para enfrentarse de una manera científica y rigurosa con la problemática específica de la sociedad en cuanto tal.

Históricamente, por tanto, la contribución histórica ha sido permanente. Ciertamente, ya antes del siglo XIX existió una reflexión acerca de la sociedad pero estuvo siempre unida a planteamientos éticos o metafísicos. Fue la prehistoria de la Sociología en la que los pensadores estuvieron más preocupados por decir como debía ser la sociedad que por conocer cómo funciona de hecho.

Como aportación científica, la Sociología nace en el siglo XIX. Comte había de utilizar por primera vez el término de sociología. No existen, sin embargo, razones para considerar a este solo autor (Comte) en una sola fecha (1839) como el único responsable del nacimiento de la Sociología. Su origen, como hemos mencionado, se debió más bien a la acu- 
mulación de una serie plural de factores intelectuales y sociopolíticos. El positivismo de Comte, la superación de los estados teológico y metafísico, el desarrollo de las ideas evolucionistas, el desarrollo industrial, la evolución hacia los ideales democráticos y la aparición del proletariado... fueron configurando una situación que requería cada vez con más urgencia el análisis y la respuesta sociológicas.

Desde la última decada del s. XIX hasta la Gran Guerra, el esfuerzo de los sociólogos se orienta en el sentido de: abandonar paulatinamente el esfuerzo evolucionista que no resistía la prueba empírica de los hechos; destacar el importante papel de los factores no-racionales en la vida social (V. Pareto); reaccionar contra los planteamientos excesivamente rígidos del positivismo (Dilthey o Weber); prolongar la figura de Marx como una orientación relevante; y adoptar un marcado carácter nacional enraizando con las tradiciones culturales de los respectivos países.

A partir de la Primera Guerra Mundial, la ruptura de los marcos nacionales así como la institucionalización académica y profesional de la disciplina, ocupan la tarea primordial de la Sociología. Como consecuencia de esta segunda orientación se produce el incremento en la cooperación interdisciplinar entre las ciencias sociales y el desarrollo de los métodos y técnicas de investigación social.

Desde un enfoque más específico, la contribución de los sociólogos se centra en el análisis de los diversos aspectos de la realidad social. Así, por ejemplo:

Max Weber (1984) en su Economía y sociedad, a través de una exposición compleja y detallada efectuada con una gran cohesión estructural, pretende estudiar desde los conceptos fundamentales de la propia sociología y de la economía hasta los diversos tipos de dominación, desde la evolución del derecho hasta los fundamentos sociológicos de la música. Desde una amplia perspectiva da cuenta del modo mas comprensivo, para emplear el término de Weber, de la evolución social, política y cultural de la humanidad. Más allá del análisis exclusivo del horizonte occidental dedica particular atención a las culturas orientales proporcionando un sólido fundamento al examen de la tensión habida entre Oriente-Occidente $\mathrm{y}$, en definitiva, trata de «fijar ciertas relaciones sociológicas dentro de la vida económica» (p. 46).

Otro clásico, Ely Chinoy (1985), en su Introducción a la Sociología, pretende explorar los perfiles de la sociedad, delimitando sus fronteras, definiendo y precisando sus conceptos fundamentales y recorriendo, aunque sea parcialmente, los sectores que la componen enfocándolos a la luz de los recientes descubrimientos de la sociología. Junto a los principios que resumen la esencia de la diversidad de hechos prestándoles categoría de ley científica, E. Chinoy (1985) examina hechos de la vida diaria que 
recogen aspectos sensibles del ser humano como la participación política, la vida familiar, la religión, la actitud profesional ante determinados hechos y fenómenos etc.

Más de una docena de profesores sociólogos españoles actuales (F. Alvira, M. D. Alvira, I. Carrasco, J. Castillo, S. del Campo, A. de Pablo, J. Díez, M. A. Durán, J. Iglesias, J. Leal, J. F. Mira, L. Rodríguez, E. Sevilla, J. F. Tezanos... (1988), reflexionan sobre la Sociología como disciplina científica, sobre la naturaleza humana y la cultura, la población y el medio, el análisis de la estratificación social etc. Partiendo del hecho de que «la Sociología es hoy una disciplina poliparadigmática» y desde una perspectiva «tolerante, abierta, nunca dogmática» (p. 14), analizan temas como la personalidad y socialización, socialización y control social, ecología humana y ecosistema social, la ciudad, la sociología urbana, el campesinado, las clases medias, la clase dominante, la clase obrera etc.

Otros autores centran su atención en determinados aspectos concretos. S. Giner (1986), por ejemplo, analiza en su Sociología el concepto de clase. En su opinión, «frente a la condición objetiva de las clases — su situación física y económica dentro de la estructura social generalexiste una conciencia colectiva de las mismas, la percepción que los miembros tienen de su propia clase y de las demás» (p. 127).

Para J. Morales y L. V. Abad (1988), por su parte, «la primera tarea sociológica consiste, paradójicamente, en definir con precisión el objeto mismo de la Sociología» (p. 29). Junto a esta misión, la aportación sociológica debe ir orientada a: la revisión histórica del objeto de la Sociología, la naturaleza social del hombre, la estructura social, los grupos sociales, la familia y parentesco, la estratificación social, la desviación y control social, el cambio social, las ideologías, la demografía mundial, los recursos, el desarrollo y modernización, las formas de organización política etc.

Otra contribución excelente es aquella que trata de proyectar, ensamblar, el pensamiento filosófico-ideológico hacia/en el ámbito de la Sociología. En este contexto se inserta, por ejemplo, el interesante trabajo del profesor J. M. Osés (1989) «La Sociología en Ortega y Gasset». Ortega, a decir de este texto, descubre pronto el valor fenomenológico y lo intenta aplicar a la tarea de una radical fundamentación del saber sociológico. A través del método histórico, el estudio analiza la influencia de los filósofos alemanes en la obra juvenil de un Ortega preocupado por los destinos de un Pueblo y una Nación que no logra encontrar su ser ni su lugar en la historia de Occidente. A través del método comparativo, trata de entresacar las posibles coincidencias y discrepancias entre las ideas sociales de Ortega y de otros pensadores de la misma época y a través del método analítico, estudia en profundidad las aportaciones orteguianas al pensamiento sociológico. 
Como afirma el Dr. Osés (1989), «en nuestro trabajo hemos procurado situar a Ortega dentro de esa corriente de pensamiento sociológico en la que su obra se inscribe y sin la cual el suyo propio pierde efectividad. Se trataría de analizar cómo los sociólogos de esa época captan una serie de cambios importantes en la estructura de la sociedad y hacen esfuerzos para ajustarla a un orden social concreto que ellos determinan» (p. 14). Así, Ortega, a través de una filosofía que se apoya en el método fenomenológico «ha intentado dar un fundamento a la sociología» (p. 312).

Revisando, finalmente, trabajos recientes recogidos por el Centro Español de Investigaciones Sociológicas, observamos que la preocupación de los sociólogos asume, asimismo, el ámbito político concreto como una dimensión esencial. Así, a modo de ejemplo, R. Inglehart (1988), de la Universidad de Michigan, analiza la cultura política y la democracia estable (pp. 45-65); G. Di Palma (1988), de la Universidad de California, Berkeley, estudia «la consolidación democrática desde una visión minimalista (pp. 68-92); U. Liebert (1988), del Instituto Universitario de Florencia, se refiere al Parlamento y la consolidación de la democracia en la Europa del Sur (pp. 93-136); C.R. Aguilera de Prat (1988), de la Universidad de Barcelona, analiza el balance y transformaciones del sistema de partidos en España, de 1977 a 1987 (pp. 137-153); L. Moreno (1988), de la Asociación Internacional de Sociología, reflexiona sobre la identificación dual y autonomía política: los casos de Escocia y Cataluña (pp. 156-194) etc.

En dicha compilación observamos, igualmente, investigaciones concretas sobre Antropología urbana, realizadas por el Comité de trabajos históricos y Científicos de París (1987), estudios sobre La opinión pública (C. Monzón, 1987), etc.

En resumen, este breve acercamiento a algunos autores e investigaciones del campo sociológico, nos ejemplariza algunas dimensiones en las que discurre el esfuerzo de la Sociología y nos deja constancia de la importancia de su contribución histórica. Como sintetizaba el propio E. Chinoy (1985) «el conocimiento sociológico y su aplicación han llegado a ser de tal interés en la actualidad que permanentemente son empleados como fuente de información objetiva, como guía útil para la acción y como importante criterio para la comprensión de la conducta humana» (p. 395).

\section{Hacia una concepción ética de la Economía y de la Política}

Es evidente que junto a la Filosofía, la Antropología y la Sociología, las Ciencias Económicas y Políticas representan también una perspectiva fundamental en el mundo contemporáneo. El análisis que estas Ciencias Sociales verifican, o pueden verificar, de los aspectos positivos y negati- 
vos de la realidad económica y política es sin duda, decisivo para el desarrollo del hombre moderno.

En efecto, la condición humana actual es tal - ha descrito E. Fromm (1983) - que la ciencia ha hecho aparecer fuerzas productivas desconocidas hasta el presente, las cuales conllevan una progresiva transformación de la materia. Simultáneamente, se han creado nuevos sistemas políticos que, en principio, parecen asegurar el desarrollo libre del individuo en una sociedad igualmente libre (pp. 7-15).

Desde una perspectiva histórica global, tres etapas principales habrían marcado el desarrollo económico-industrial. La primera (desde mediados del s. XVIII hasta finales del s. XIX) estaría caracterizada por la activación de la industria textil y más tarde de la siderometalurgia impulsadas por la introducción de la máquina de vapor. La segunda (desde finales del s. XIX hasta mitades de nuestro siglo) estaría representada por la invención de la turbina y el motor de explosión interna y, por la utilización del petróleo y la electricidad. La tercera (a partir de mediados de nuestro siglo) viene determinada por la utilización de la energía atómica, la terciarización de la economía, la tecnología química y biológica, la implantación de la electrónica, la robótica y la informática etc.

El análisis que las Ciencias Sociales efectúan sobre este proceso histórico es tan importante que M. Navarro López (1984) lo ha calificado de verdadero «banco de pruebas para diferentes hipótesis y teorías sociológicas y económicas» (p. 70).

Efectivamente, de su estudio deducimos que cada una de las etapas que configuran el proceso económico-industrial determina de algún modo una específica situación laboral de relevantes consecuencias para la conducta humana.

En el transcurso de su evolución, los diversos modelos económico-industriales crean, junto a evidentes avances, un modelo de ser productivo no siempre satisfactorio desde el punto de vista del desarrollo humano.

A lo largo de su proceso, los métodos de trabajo se fueron transformando condicionados por un mercado impersonal, la mercancía se produce de un modo uniforme, el proceso de producción se simplifica, se introduce la máquina y la división del trabajo etc.. La conjunción de estos factores desemboca en la consolidación del capitalismo y en la industrialización.

En este proceso de desarrollo industrial, el aumento del comercio y de las relaciones monetarias no siempre ha sido un elemento liberalizador del hombre sino que por el contrario, como describe M. Dobb (1984), «fue a menudo acompañado por una intensificación de la servidumbre» (p. 57). La misma máquina que inicialmente libera al operario industrial de tareas penosas y acrecienta las capacidades productivas, crea también 
problemas de dependencia, automación y estandarización que configuran buena parte de la patología del trabajo industrial.

El trabajador va funcionando progresivamente como un ser anónimo dentro de las grandes cadenas industriales y se convierte en un átomo económico que se mueve bajo una dirección empresarial igualmente burócrata y automatizada. Paralelamente esta estructura económico-productiva crea la sociedad de consumo que obliga a comprar permanentemente los objetos producidos.

La producción laboral que en los Manuscritos del 44 se entendía como el intento de reproducir la naturaleza y gracias a la cual la naturaleza aparece como la obra y la realidad (del hombre) (p. 64) da paso ahora al concepto de ganancia y provecho, el cual se convierte en principio-guía de la conducta humana. Gradualmente el mercado se transforma en la base de las relaciones humanas. El ser humano, concreto e individual, va dejando progresivamente de ocupar el centro del sistema en aras de la producción. El hombre deja de ser «la medida de las cosas» en la esfera económica.

El concepto de la competencia se constituye en elemento esencial de mercancías, capacidades y personas. El hombre no constituye ya un fin en sí mismo y se convierte en un medio para los intereses del gran mecanismo impersonal económico. La axiología de la existencia humana queda invertida. Las cosas, el capital, ocupa un puesto preferencial sobre la creatividad, el trabajo. De esta forma, el conflicto entre capital y trabajo aparece como algo más que el simple enfrentamiento de dos clases. Es, más bien, la problemática entre dos principios de valoración.

Frente a esta situación creada por el desarrollo económico-industrial, es posible que las Ciencias Sociales deban plantearse la recuperación humana de la economía. «Es preciso, decía Mounier ya en 1972, reivindicar una economía para la persona» (p. 131). Recogiendo la frase de Emerson: no son las cosas (la economía, la máquina, el consumo, los intereses mercantiles y políticos...) las que deben dominar al hombre sino, por el contrario, son las fuerzas vitales y creativas las que deben tomar las riendas y manejar lo inerte.

En una sociedad de consumo como la nuestra, es necesario que el hombre consiga ir mas allá del «mundo feliz» de Huxley en el que los sujetos se sienten superficialmente satisfechos por el hecho de poseer cada vez más objetos, y alcanzar el fondo de la naturaleza humana individual y social, aquello que, según la Invitación a la Etica de F. Savater (1982) «alienta al hombre y en el hombre» (p. 10). Tener y ser - ha dicho E. Fromm (1981) - son dos modos básicos de experiencia que «determinan la distinción entre los caracteres de los individuos y los diversos tipos de caracteres sociales» (p. 43). 
Se trata, por consiguiente, de dar proporciones verdaderamente humanas a los sectores económicos y políticos. La economía debe estar al servicio del hombre, de todo el hombre y de todos los hombres y no, de forma inversa, el hombre al servicio de la economía. «La revolución de la esperanza — afirma Fromm (1980) — nos hace creer que tal posiblidad existe y que ella debe basarse en el análisis de nuevas alternativas y opciones y en las acciones concertadas para hacerlas realidad» (p. 34).

En esta óptica, el hombre podrá perfeccionar su situación solamente si logra dominar la sociedad económica y política creada por él y subordinar sus mecanismos a la finalidad de la felicidad humana. Es necesario un cambio en nuestro sistema social, aseveraba el economista-humanista E. F. Schumacher. Sobre bases puramente económicas, corroboraban Messavovic, Pestel y Ehrlich, se impone una nueva ética, una nueva actitud ante la naturaleza, la solidaridad y la cooperación humanas.

Desde el punto de vista político, es preciso simultáneamente profundizar en el concepto de democracia, de tal manera que, junto a las libertades públicas, se logre un efectivo desarrollo de los individuos. Cualquier renuncia del yo auténtico, de la propia individualidad, en aras de sustitutos económicos o políticos, individuales o colectivos, supondrá de alguna forma un refugio de evasión de la libertad, un miedo a la libertad (F. Fromm, 1981), Y, ciertamente, como categorizaba J. P. Sartre (1967) en su introducción a la Crítica de la Razón Dialéctica, «on n'asservit l'homme que s'il est libre» (p. 249).

En suma, la aportación de una concepción ética desde las Ciencias Económicas y Políticas en la recuperación de la dimensionalidad humana de sus correspondientes realidades, puede ser fundamental para el presente y futuro del hombre actual y de la estructura social.

\section{Las Ciencias Sociales y el equilibrio psicosocial}

Una última aportación de las Ciencias Sociales, que queremos mencionar a modo de ejemplo, es su contribución al equilibrio psicológico de los individuos y, como consecuencia, al equilibrio de la sociedad.

En conexión con lo expuesto en los apartados anteriores, es evidente que el desarrollo de la economía y de la política influyen en la construcción del mundo cultural y de los valores y éstos, a su vez, configuran la personalidad de los sujetos y de las colectividades. De forma correlativa, cuando el desarrollo tecnológico se produce de forma unilateral o cuando el proceso de la realidad social se lleva a cabo al margen de la dimensión antropológica, tal influencia puede abocar a una situación de patología psicosocial. 
En principio, parece ser fácilmente asumible el hecho de que toda estructura socioeconómica determina de alguna forma el sistema cultural y axiológico de las personas y de que éste condiciona interactivamente el proceso social:

Marx (1970) en La Ideología Alemana sostenía ya que la economía condiciona el desarrollo social y cultural. Los hombres que desarrollan su producción material y su intercambio material, afirmaba, cambian también, al cambiar esta realidad, su pensamiento y los productos de su pensamiento. «No es la conciencia la que determina la vida sino la vida la que determina la conciencia» (p. 26). Paralelamente, Engels enunciaba en una de sus cartas que los hombres hacen la historia pero en un medio dado que los condiciona. R. Dahrendorf (1962), por su parte, al describir el cambio de las sociedades pre e industrial consideraba que la modificación singular entre ambas no estribaba tanto, al menos en su período inicial, en la cuestión económica cuanto «en la supresión simultánea de valores que el orden de la sociedad preindustrial garantizaba y legitimaba» (p. 20). Del mismo modo, cuando Weber escribió La ética protestante y el espíritu del capitalismo, no intentó negar, como algunas opiniones simplistas han pretendido, la influencia que la economía puede tener en la vida social y cultural, sino afirmar que la acción social es demasiado compleja como para prestarse a explicaciones reduccionistas y que, al menos en un caso (la aparición del capitalismo racionalista), la evolución de la economía se vio decisivamente influenciada por factores culturales y éticos (la ética protestante calvinista).

Desde una óptica más concreta, G. Dalton (1982), al analizar Los Sistemas Económicos y la Sociedad, enfatiza igualmente la influencia de los cambios socioindustriales en la vida cotidiana de las personas. «Todos ellos, dice, han introducido modificaciones en nuestro desayuno, en la forma de emplear nuestro ocio, en el tipo de edificaciones en que vivimos, en la manera de hacer el amor, de ganarnos el sustento y en el número de los que van a la iglesia» (p. 60).

La economía, por tanto, - han sintetizado S. Dormido, J. Morales y L. V. Abad (1990) - es un subsistema cuyo funcionamiento no puede explicarse mas que admitiendo «su interrelación recíproca y dinámica con el resto de los subsistemas sociales, culturales, políticos y psicológicos» (p. 16).

Así pues, si el desarrollo socioeconómico y sociopolítico está estrechamente relacionado con el desarrollo cultural y psicológico de los individuos y de las sociedades, es imprescindible que aquel se produzca de una forma antropológica - en cuyo proceso el papel de las Ciencias Sociales es esencial - para conseguir el desarrollo armónico de éste. Más aún, el hombre, en opinión de los psicólogos sociales, no sólo es homo 
oeconomicus movido exclusivamente por incentivos materiales sino además ser social ligado a la dinámica de los factores psicosociales. La satisfacción personal, la motivación, la emocionalidad, el desarrollo del propio yo en la interacción social, la adaptación de la naturaleza humana a la propia estructura social etc., son, entre otros factores, constitutivos de su propia esencia.

Dicho de otro modo, si queremos analizar el estado general del hombre moderno e investigar los factores que conforman su equilibrio o desequilibrio personal es preciso que estudiemos, junto a los principios ideológicos que los sustentan, la influencia de las condiciones específicas de nuestro modo de producción y de nuestra organización sociopolítica y cultural sobre la naturaleza humana. Dada la mutua relación existente entre organización social y psicología humana - ha dicho E. Fromm en su Psicoanálisis de la Sociedad Contemporánea (pp. 71-90)— podemos afirmar que la estructura socioeconómica de la sociedad moldea el carácter del hombre y la naturaleza humana, a su vez, modifica las condiciones sociales en que vive.

Como consecuencia de la socialización, ha corroborado G. Rocher (1979), «algunos elementos de la sociedad y de la cultura pasan a ser parte integrante de la estructura de la personalidad psíquica» (p. 136).

En tal contexto, no es de extrañar que la última edición de la Revista de Psicología Social (1990) trate de analizar esta relación sociedad-aspectos psicosociales, no sólo desde una perspectiva epistemológica sino también desde el estudio de aspectos tan concretos como: los roles sexuales y personalidad (Avia, D.; Carrillo, J. M. y Rojo, N.), televisión y cultura política (Roda, R.; Gerbner, G.; Gross, L.; Morgan, M. y Signorielli, N.) etc.

En lo que respecta a la posible conexión entre sociedad y patología, K. Horney (1981) que, junto a Adler, Sullivan, Fromm, Erickson y otros autores, ha centrado su análisis en las influencias culturales y sociales sobre la personalidad del individuo, ha recogido muchos de los rasgos con que describíamos anteriormente nuestra sociedad industrializada (impersonalidad laboral, competitividad, consumismo, miedo a la libertad...) y los ha calificado como rasgos socioculturales básicos para conformar la personalidad neurótica de nuestro tiempo (pp. 231-236).

Ello refleja que la enfermedad mental la encontramos en la esencia misma de la orientación cultural y a través de la estructura social. De ahí que, en nuestra opinión la psicología clínica deba trabajar intensamente asociada con los métodos y las conclusiones de las Ciencias Sociales. El sometimiento de todo problema de personalidad, individual y colectiva, a sus correlaciones sociales de tiempo-espacio-cultura, ha dicho C. Esteva en su Cultura, Sociedad y Personalidad (1978), «constituye una de las 
maneras más comprensivas de enfocar el problema de la salud individual-social en sus proporciones más dinámicas y reales» (p. 174).

En síntesis, las Ciencias Sociales, en su análisis de la interacción sociedad-equilibrio/desequilibrio psicológico, constituyen un pilar fundamental para el desarrollo armónico del hombre actual tecnologizado y, por ende, para el desarrollo psicológico de la sociedad.

\section{A modo de conclusión}

En nuestra exposición hemos tratado de esbozar algunas de las aportaciones que las Ciencias Sociales pueden ofrecer al hombre de hoy. Posiblemente no sean las más importantes ni desde luego pretenden ser, en modo alguno, exhaustivas. Simplemente, nos sugieren algunos de los campos en los que se mueven las Ciencias Sociales y que nos hacen entrever su importancia para el hombre actual inmerso en un contexto tecnificado e industrializado.

La Filosofía contemporánea, en su intento de comprender y explicar la realidad humana, nace como respuesta a los problemas ideológico-existenciales planteados por la transformación científica y social. La Antropología, mas allá de los objetivos unilaterales de las ciencias específicas, trata de estudiar al hombre en cuanto tal, en cuanto hombre, a través de sus distintos niveles: biológico, etnográfico-paleontológico, etnológico, sociológico, cultural, psicológico y filosófico. La Sociología, surge para establecer un planteamiento científico y riguroso de la concreta y diversa problemática social y para intentar construir una ciencia específica de dicha sociedad. La concepción Etica de la Economía y de la Política, trata, desde el reconocimiento pleno de ambas realidades, de recuperar la dimensionalidad humana de las mismas poniéndolas al servicio del hombre, de todos los hombres y de todo el hombre. Las Ciencias Sociales pretenden, de este modo, analizar las graves patologías psicosociales surgidas de la insuficiencia-deficiencia de la actual estructura socio-económica y socio-política.

A la luz de esta reflexión, creemos que, desde el punto de vista psicosocial, es preciso reivindicar para el desarrollo de los individuos y de las sociedades un equilibrio armónico entre lo económico-tecnológicoindustrial y lo humano-social-psicológico. Y ello, desde el propio proceso educativo.

En un momento en el que en en nuestro País se proyectan nuevos horizontes universitarios, sería de desear que tal equilibrio tecnológico-psicosocial quedara reflejado en la planificación y estructura de la Universidad.

Al menos por estas breves consideraciones, estamos convencidos de que las Ciencias Sociales constituyen una contribución fundamental. 


\section{Bibliografía}

ARON, R.: Estudios sociológicos. Espasa Calpe. Madrid, 1989.

ASHFORD, D.: La aparición de los estados de bienestar. Ministerio de Trabajo. Madrid, 1989.

BARBERÁ, J.: Los países industrializados ante las nuevas tecnologías. Vol. II: Experiencias tecnológicas e impactos económicos y sociales. Fundesao. Madrid, 1986.

BAstide, R.: Antropología aplicada. Amorrotu. B. Aires, 1977.

BERGER, P.: La revolución capitalista. Península. Barcelona, 1989.

CAMPO, S. del: La sociedad de clases medias. Espasa Calpe. Madrid, 1989.

CAMPO, S. del: Tratado de sociología. 2 Vol. Taurus. Madrid, 1988.

CAssirer, E.: Antropología filosófica. Introducción a la filosofía de la cultura. F.C.E. México, 1977.

Castello, A.: El desafío de los años 90. Fundesco. Madrid, 1986.

CASTElls, M.: Nuevas tecnologías, economía y sociedad en España. REIS 38, 1987.

CAstillo, J. J.: Crisis del trabajo y cambios sociales. Introducción. REIS 38, 1987.

Cencillo, L.: Curso de Antropología Integral. Parte I. ${ }^{a}$. Syntagma. Madrid, 1970.

COLOMER, A.: El trabajo ante la encrucijada tecnológica. ¿Hacia una revisión de la ética social?. Sistema, 92, 1989.

CHINOY, E.: La sociedad. Una introducción a la sociología. F.C.E. México, 1985.

DAHRENDORF, R.: Las clases sociales y su conflicto en la sociedad industrial. RIALP. Madrid, 1962.

Dalton, G.: Sistemas económicos y sociedad. Alianza. Madrid, 1982.

DE Vos, G.: Antropología Psicológica. Anagrama. Barcelona, 1981.

DoBB, M.: Estudios sobre el desarrollo del capitalismo. Siglo XXI. Madrid, 1984.

Dormido, S.; Morales, J.; Vicente, L.: Sociedad y nuevas tecnologías. Trotta. Madrid, 1990.

Duncan, G.: Historia de la sociología. Labor. Barcelona, 1981.

Foucault, M.: Les mots et les choses. Gallimard. París, 1966.

Fromm, E.: La revolución de la esperanza. F.C.E. Madrid, 1980.

Fromm, E.: Tener o ser. F.C.E. Madrid, 1981.

FromM, E.: El miedo a la libertad. Paidós. Barcelona, 1981.

Fromm, E.: La condición humana actual. Paidós. B. Aires, 1983.

Fromm, E.: Psicoanálisis de la sociedad contemporánea. F.C.E. Madrid, 1983.

GARCÍA, F. M.: El análisis de la realidad social. Alianza. Madrid, 1986.

GARMENDIA, J. A.: Sociología industrial y de la empresa. Aguilar. Madrid, 1987.

GEERTZ, C.: La Interpretación de las culturas. Gedisa. Barcelona, 1990.

GINER, S.: Sociología. Nexos. Barcelona, 1986.

GINER, S.: Sociedad y política. Espasa Calpe. Madrid, 1989.

GorRI, A.: J.P. Sartre. Un compromiso histórico. Evolución ontológico-social de una psicología fenomenológica. Anthropos. Barcelona, 1986.

GUIOT, J.: Organizaciones sociales y comportamientos. Herder. Barcelona, 1985.

HARRIS, M.: Introducción a la antropología general. Alianza. Madrid, 1989.

HORNEY, K.: La personalidad neurótica de nuestro tiempo. Paidós. Barcelona, 1981.

IBÁÑEZ, T.: Ideologías de la vida cotidiana. Barcelona, 1989. 
INGLEHART, R.: «Cultura. política y democracia estable». Rev. Española de Investigaciones Sociológicas. C.I.S. n. ${ }^{\circ} 42$, 1988, pp. 45-65.

JeAnson, F.: La phénoménologie. Téqui. París, 1952.

LACROIX, J.: Marxisme, existentialisme, personalisme. P.U.F. París, 1955.

LAFOnTAIne, O.: La sociedad del futuro. Sistema. Madrid, 1989.

LÉVI-STRAuss, C.: Antropología estructural. Eudeba. B. Aires, 1976.

LeVINAS, E.: En découvrant l'existence, avec Husserll et Heidegger Vrin. París, 1949.

LIEBERT, U.: «Parlamento y consolidación de la democracia en la Europa del Sur». Rev. C.I.S. n. ${ }^{\text {4 }}$, 1988, pp. 93-136.

MAIR, L.: Introducción a la antropología social. Alianza. Madrid, 1982.

MARTín, L.: Diez lecciones de sociología. México, 1988.

MARX, K.: Le Capital. Libro III: Critique de l'économie politique. V. Giard-E. Brière. París, 1901.

MARX, K.: Manuscritos de 1844. París, 1962.

MARX, K.:Miseria de la filosofía. Aguilar. Madrid, 1969.

MARX, K.: La ideología alemana. Barcelona, 1970.

Morales, J. y ABAD, L. V.: Introducción a la Sociología. Tecnos. Madrid, 1988.

Mounier, E.: Manifiesto al servicio del personalismo. Taurus. Madrid, 1972.

MOUNIER, E.: Qu'est-ce que le personalisme?. Dénöel. París, 1946.

MuÑoz, R.: Crisis y futuro del estado de bienestar. Alianza. Madrid, 1989.

NAvarro LóPez, M.: Economía. En S. del Campo. Tratado de Sociología. Vol. 2. Taurus. Madrid, 1984.

OfFe, C.: Partidos políticos y nuevos movimientos sociales. Sistema. Madrid, 1989.

OSES, J. M.: La Sociología en Ortega y Gasset. Anthropos. Barcelona, 1989.

PINO, J. del: La teoría sociológica. Tecnos. Madrid, 1989.

RADCLIFFE-BROWN, A. R.: Estructura y función en la sociedad primitiva. Planeta Agostini. Barcelona, 1986.

REY, J.: El conflicto social. S. XXI. Madrid, 1985.

ROCHER, G.: Introducción a la sociología general. Herder. Barcelona, 1979.

SARRIBLE, G.: Problemas y conflictos de la población mundial. Sistema 93, 1989.

SAUQuillo, J.: Michel, Foucault: una filosofía de la acción. C.E.C. Madrid, 1989.

SARTRE, J. P.: Questions de méthode. Gallimard. París, 1976.

SAVATER, F.: Invitación a la ética. Anagrama. Barcelona, 1982.

SCHAFF, A.: ¿Qué futuro nos aguarda?. Crítica. Barcelona, 1985.

SCHNEIDER, M.: Neurosis y lucha de clases. S. XXI. Madrid, 1979.

TEZANos, J. F.: La explicación sociológica. Una introducción a la sociología. UNED. Madrid, 1990.

TOURAINE, A.: El postsocialismo. Planeta. Barcelona, 1982.

Varios: Europa 1995. Nuevas tecnologías y cambio social. Fundesco. Madrid, 1986.

Varios: Revista de Psicología Social. Vol. 5, 1, 1990, pp. 2-128.

Varios: Revista de Investigaciones Sociológicas. C.I.S., n. ${ }^{\circ}$ 42, 1988.

WEBER, M.: La ética protestante y el espíritu del capitalismo. Península. Barcelona, 1969.

WEBER, M.: Economía y sociedad. F.C.E. México, 1984. 